\title{
Analisis Routing Protokol Optimized Link State Routing (OLSR) Pada Raspberry Pi
}

\author{
Ulfa Septilia Permatasari ${ }^{1}$, Indrastanti Ratna Widiasari ${ }^{2}$ \\ ${ }^{1,2}$ Fakultas Teknologi Informasi Universitas Kristen Satya Wacana \\ Jl. Dr. O. Notohamidjojo 1-10, Salatiga 50711, Indonesia \\ Email : ${ }^{1} 672011228 @$ student.uksw.edu, ${ }^{2}$ indrastanti@gmail.com
}

\begin{abstract}
Optimized Link State Routing (OLSR)is one of the two standard for mesh networks. OLSR is a link state routing protocol, which use hallo message and topology control (TC) to determine the link state information across the mobile ad-hoc network. OLSR is widely used in the wireless mesh network. Raspberry Pi is a mini computer which can be used as a node router to replace the function of a router in a wireless mesh network. In this research, Raspberry Pi is used as a router nodes to determine the performance of routing protocol OLSR. The parameters used to measure its performance is self-configure time, self-healing and bandwidth usage. The test results showed that the use of routing protocols OLSR on the Raspberry Pi in a wireless mesh network proved able to repair itself if there is a problem on the network since it has ability to self-configure and self-healing.
\end{abstract}

Keywords: Optimized Link State Routing, Raspberry Pi, Wireless Mesh Network, SelfConfigure, Self-Healing

\begin{abstract}
Abstrak
Optimized Link State Routing (OLSR) merupakan salah satu dari dua standart internet untuk jaringan mesh. OLSR routing protokol link-state yang menggunakan message hello dan topologycontrol(TC) untuk mengetahui informasi link-state di seluruh jaringan mobile ad-hoc. OLSR banyak digunakan pada wireless mesh network. Raspberry Pi yang merupakan mini komputer dapat digunakan sebagai node router untuk menggantikan fungsi dari router dalam wireless mesh network. Dalam penelitian ini, digunakan Raspberry Pi sebagai node router untuk mengetahui performansi dari routing protokol OLSR.Parameter yang digunakan untuk mengukur performansinya adalah waktu selfconfigure, self-healing dan penggunaan bandwidth. Penggunaan routing protokol OLSR pada Raspberry Pi dalamwireless mesh network terbukti dapat memperbaiki dirinya sendiri jika ada masalah pada perangkat jaringannya karena memiliki kemampuan self-configure dan self-healing.
\end{abstract}

Kata kunci: Optimized Link State Routing, Raspberry Pi,Wireless Mesh Network, SelfConfigure, Self-Healing 


\section{Pendahuluan}

Optimized Link State Routing (OLSR) adalah routing protokol link-state yang proactive, yang menggunakan message hello dan topologycontrol(TC) untuk mengetahui informasi link-state di seluruh jaringan mobile ad-hoc. OLSR banyak digunakan dan sudah teruji keandalannya karena sangat cepat dan menggunakan sedikit CPU time yang menyebabkan penggunaan baterai lebih sedikit dari embedded dan portabledevice. OLSR merupakan salah satu dari dua standart internet untuk jaringan mesh[1]. OLSR sering dijalankan pada wireless mesh network.

Wireless mesh network merupakan jaringan mobilead-hoc yang terkoneksi peer-to-peer ke jaringan. Wireless mesh networkmemiliki jangkauan yang luas karena setiap node tidak hanya bertindak sebagai host tetapijuga dapat berfungsi sebagai sebuah router untuk meneruskan paket-paket informasi yangakan dikirim menuju node lain yang mungkin tidak dapat menjangkau tempat yang inginditujunya karena keterbatasan jarak.Wireless mesh networkmemiliki kelebihan, dimana jika koneksi yang dilakukannya gagal, maka akan melakukan routing kembali dan dapat mengorganisasikan dirinya sendiri, sehingga koneksi tidak rentan putus.

Dalam penelitian ini digunakan routing protokol OLSR dan Raspberry Pi sebagai node. Perancangan jaringan dilakukan untuk pengujian terhadap performansi dari routing protokol OLSR pada Raspberry Pi dalamWireless mesh network. Data yang diambil pada penelitian ini berupa waktu self-configure dan self healing yang dibutuhkan, selain itu juga penggunaan bandwidth.

Penelitian ini bertujuan untuk mengetahui performansi routing protokol OLSR pada Raspberry Pi sebagai node dalam wireless mesh network. Dengan melihat parameter waktu self-configure, self-healing dan penggunaan bandwidth pada penelitian ini, maka dapat diambil kesimpulan sesuai dengan hasil yang didapatkan. Penelitian ini diharapkan dapat bermanfaat untuk bahan pertimbangan bahwa Raspberry Pi yang merupakan mini komputer dengan daya rendah juga dapat menjadi node mesh karena komponen utama wireless mesh network adalah suatu perangkat yang selain dapat berperan sebagai sumber trafik juga dapat berperan sebagai router yang mampu merutekan trafik dari sumber ke tujuan.

\section{Tinjuan Pustaka}

Pada penelitian lain membahas tentang implementasi protokol routing OLSR pada Wireless Mesh Network dengan wireless router TP-Link menggunakan OpenWRT Barrier Breaker dengan paket OLSR Daemon untuk menguji kinerja jaringan dengan parameter self-configure, self-healing, jitter dan bandwidth. Hasil yang didapatkan dari penelitian tersebut adalah protokol routing OLSR terbukti dapat memperbaiki dirinya sendiri jika ada masalah pada perangkat jaringan karena 
AITI: Jurnal Teknologi Informasi

Volume 16 No. 2 Agustus 2019, 151-164

memiliki kemampuan self-healing dan self-configure, sehingga jika ada perubahan topologi pada jaringan maupun ada jalur yang putus antara node masih bisa berkomunikasi. Pada pengujian jitter menunjukkan bahwa protokol OLSR memilih jalur tercepat walaupun harus melalui hop yang lebih banyak [3].

Berdasarkan penelitian terdahulu yang membahas tentang penggunaan protokol routing OLSR pada wireless mesh network menggunakan hardware yang berbeda yaitu wireless router LinkSys dan wireless router TP-Link, dengan firmware opensource OpenWRT yang hanya berbeda versi saja maka akan dilakukan penelitian tentang penggunaan routing protokol OLSR pada wireless mesh network menggunakan Raspberry Pi dengan sistem operasi Raspbian Jessie yang berbasis Debian ARM guna menguji performansinya. Parameter yang digunakan untuk menguji performansi adalahself-healing, self-configure,dan penggunaan bandwidth, karena routing protokol OLSR dalam wireless mesh routing memiliki karakteristik utama yaitu self-configure dan self-healing yang dapat mengkonfigurasi dan memperbaiki dirinya sendiri, dengan kata lain mampu menjaga konektivitas antar node apabila terjadi kerusakan pada salah satu node. Pengujian penggunaan bandwidth dengan kondisi jumlah hop berbeda, digunakanuntuk mendapatkan data tentang kinerja penggunaan bandwidth pada setiap node mesh dalam sistem multihop pada wireless mesh network..

Wireless mesh network adalah jaringan komunikasi terdiri dari node radio yang terorganisir dalam topologi mesh. Wireless mesh network terdiri dari dua node yaitu mesh client dan mesh router. Para mesh client biasanya smartphone, laptop, dangadget yang memiliki fitur wireless lainnya sementara untuk mesh router meneruskan koneksi ke dan dari gatewayatau dapat dikatakan sebagai jaringan backbone[4].Adapun karakteristik yang dimiliki oleh Wireless Mesh Network yang mempengaruhi kinerjanya adalahmulti-hop wireless network, kemampuan selfforming, self-healing, self-organizing serta mendukungad-hoc networking, tingkat mobilitas tergantung dari jenis node, dapat mengakses ke berbagai jenis teknologi jaringan lainnya, dependensi terhadap pemakaian daya tergantung dari jenis node $[5]$.

OLSR merupakan salah satu jenis dari proactive routing protocol yang biasa digunakan dalam jaringan ad-hoc. Protokol ini melakukan pertukaran pesansecara periodik dalam rangka menjaga informasi topologi jaringan yang ada pada setiap node.Setiap node mengirimkan paket kontrolnya masing-masing secara periodik sehingga dapat mentoleransi terjadinya loss dari beberapa paket pada saatsaat tertentu akibat dari tubrukan data ataupun akibat gangguan transmisi lainnya. OLSR menggunakan multihop routing dimana setiap node menggunakan informasi routing terbaru yang ada pada node tersebut dalam mengantarkan sebuah paket informasi.Secara umum OLSR memiliki langkah-langkah kerja, yaitu link sensing, neighbour detection, MPR selection, pengiriman TC (Topology Control) messages, dan route calculation [6]. 


\section{Metode Penelitian}

Penelitian yang dilakukan, diselesaikan melalui tahapan penelitian yang terbagi dalam empat tahapan, yaitu: (1) Menentukan topologi jaringan, (2) Menentukan spesifikasi perangkat, (3) Melakukan instalasi software, dan (4) Melakukan konfigurasi jaringan.

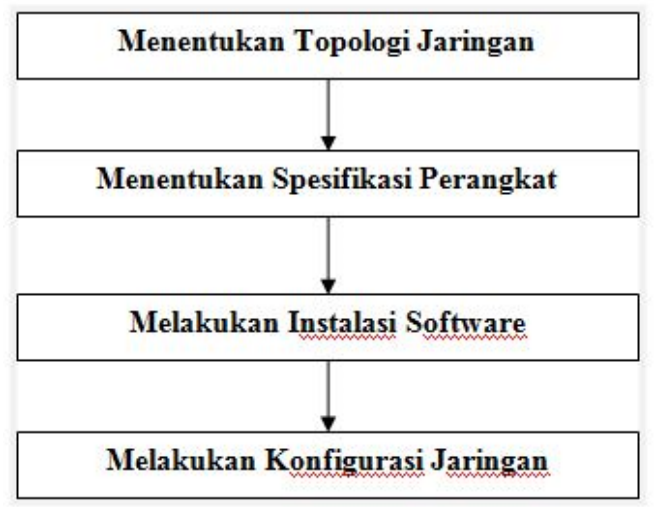

Gambar 1 Tahap - Tahap Penelitian

Tahap - tahap penelitian pada Gambar 1, dapat dijelaskan sebagai berikut. Tahap pertama: menentukan topologi jaringan. Hal ini dilakukan agar dapat menentukan dan membuat jaringan yang dibentuk oleh node router dan node client. Topologi jaringan yang dibuat disesuaikan dengan konsep wireless mesh network. Adapun topologi jaringan yang digunakan seperti pada Gambar 2.

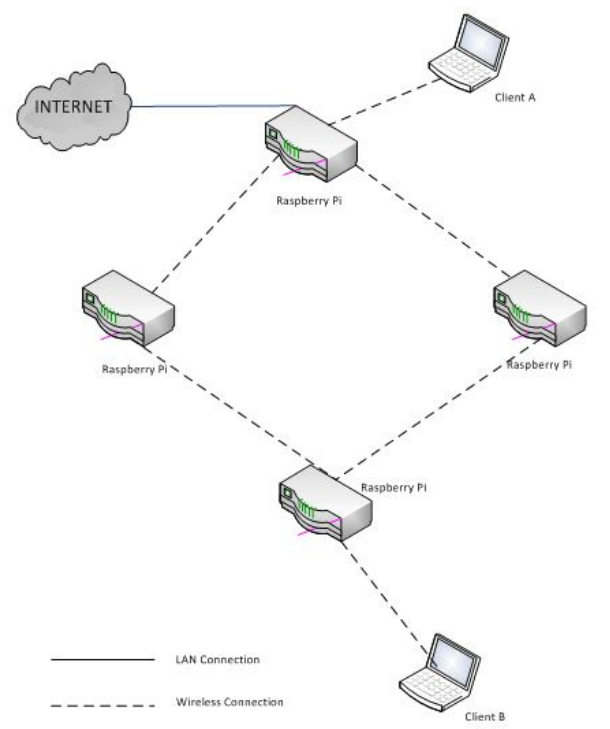

Gambar 2 Perancangan Topologi Jaringan

Node router yang digunakan sebanyak empat buah agar dapat melakukan perpindahan jalur routing sesuai dengan cara kerja wireless mesh network. Salah 
AITI: Jurnal Teknologi Informasi

satu node router terhubung dengan internet menggunakan kabel, dan menjadi gateway bagi node router lain yang terhubung secara nirkabel agar dapat terkoneksi ke internet. Ada dua client yang digunakan, yaitu clientA dan client B.

Tahap kedua: Penentuan spesifikasi perangkat dilakukan agar dapat mengetahui perangkat yang sesuai dan dapat berjalan dengan baik sesuai dengan kebutuhan wireless mesh network. Adapun perangkat yang digunakan dapat dispesifikasikan menjadi dua, yaitu perangkat keras (hardware) dan perangkat lunak (software). Spesifikasi hardware berdasarkan topologi jaringan yang digunakan dalam penelitian, dibutuhkan empat buah node router (Raspberry Pi).

Wireless usb adapter juga dibutuhkan empat buah, yang digunakanuntuk dapat terhubung secara nirkabel pada jaringan. Wireless usb adapter yang digunakan harus mendukung mode ad-hoc, maka dari itu digunakan wireless usb adapter dengan merkTP-Link seri TL-WN722N. Spesifikasi software yang digunakan pada penelitian ini ada dua, yaitu software untuk node router dibutuhkan sistem operasi Raspbian Jessie 4.4 yang berbasis Debian ARM, aplikasi routing protokol OLSR Daemon (OLSRd) dan aplikasi untuk menguji performansi jaringan digunakan Iperf.

Tahap ketiga: Instalasi software dilakukan pada node router dan node client, agar wireless mesh network dapat berjalan dengan baik. Pada node router dilakukan instalasi Raspbian Jessie versi 4.4 yang merupakan sistem operasi berbasis Debian ARM yang khusus digunakan untuk perangkat keras Raspberry Pi, selain itu juga instalasi paket OLSRd yang merupakan tools routing protokol OLSR yang dirancang untuk mempermudah konfigurasi Raspberry Pi sebagai wireless node. Serta aplikasi Iperf yang digunakan untuk menguji performansi pada jaringan.

Tahap keempat: Konfigurasi jaringan merupakan hal yang terpenting dalam tahapan penelitian ini, dimana sangat menentukan berhasil atau tidaknya sistem. Beberapa hal yang perlu diperhatikan dalam mengkonfigurasi sebuah noderouter dan node client dalam suatu jaringan agar dapat bekerja dengan baik adalah pengalamatan dan konfigurasi routing. Pengalamatan harus dilakukan pada setiapinterfacenode router dan node client dalam wireless meshnetwork dengan menggunakan Ipv4.Pengalamatan untuk interface node router pada LAN interface maupun wirelessinterface.

Kode Program 1 Pengalamatan interface pada Raspi 1

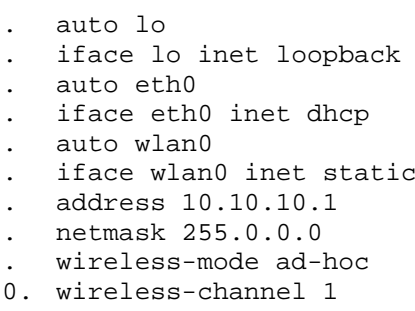


11. wireless-essid MESH

12. iface default inet dhcp

Kode Program 2 Pengalamatan interface pada Raspi 2

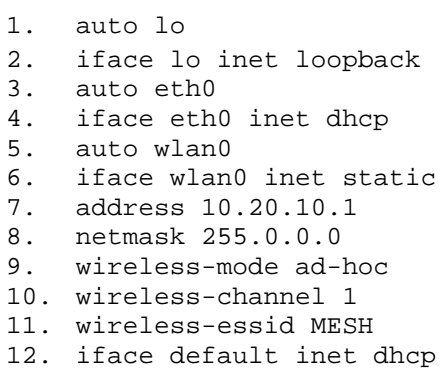

Kode Program 3 Pengalamatan interface pada Raspi 3

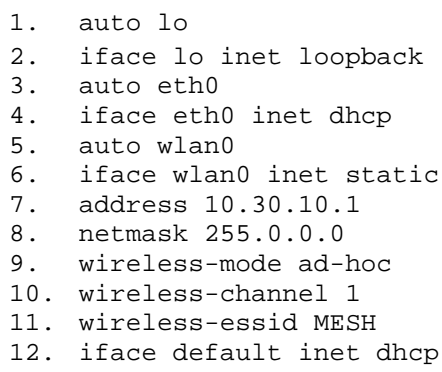

Kode Program 4 Pengalamatan interface pada Raspi 4

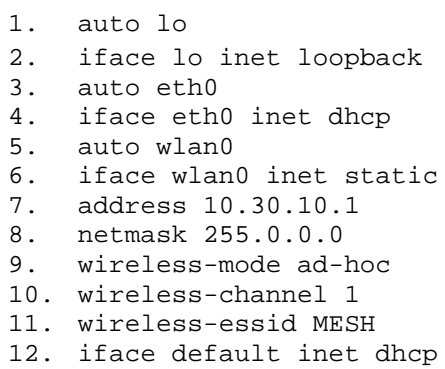

Pengalamatan pada interface node client (laptop) ini secara static jika terhubung denganwireless meshnetwork melalui koneksi wireless, yaitu dengan terkoneksi dengan wireless meshnetwork bernama ssid "MESH" dan kemudian mengubah alamat pada interface wireless laptop seperti pada Gambar 3 dan Gambar 4. 
AITI: Jurnal Teknologi Informasi

Volume 16 No. 2 Agustus 2019, 151-164

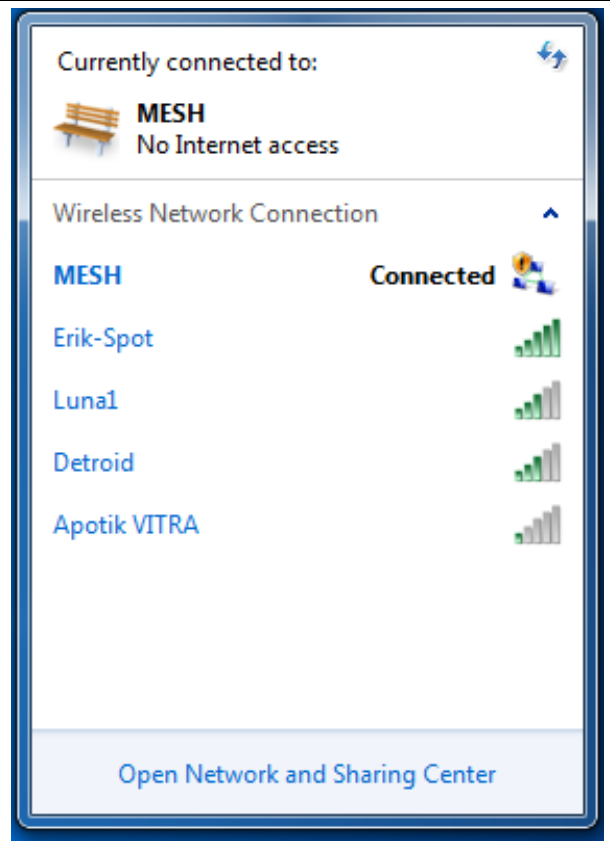

Gambar 3 Ad-hocWireless Mesh Network

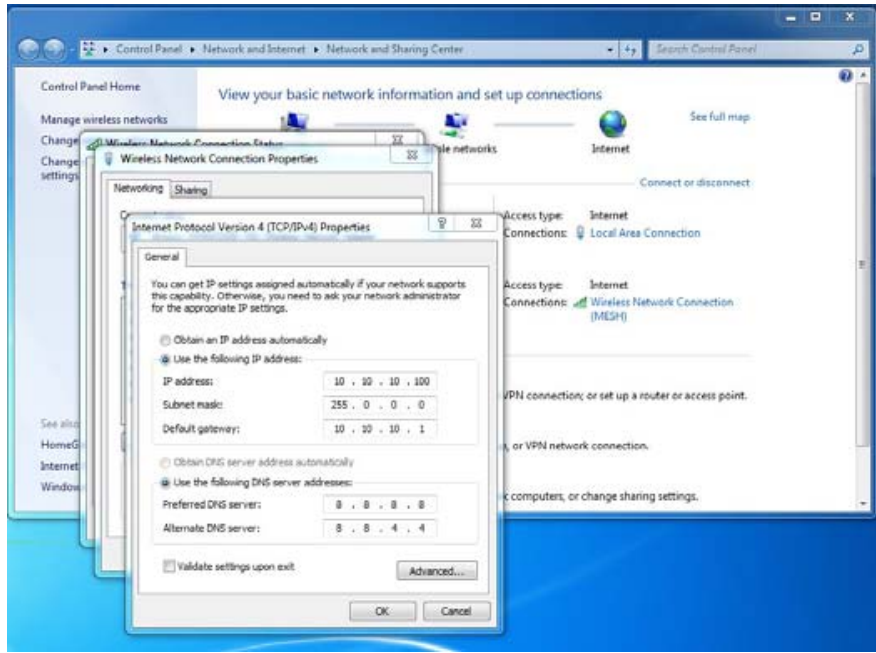

Gambar 4 Pengalamatan Interface Pada Node Client

Konfigurasi routing dapat dilakukan dengan mengubah file olsrd.conf yang terdapat pada /etc/olsrd/olsrd.conf.

Kode Program 5 Konfigurasi routing pada Raspi

$\begin{array}{lll}\text { 1. } & \text { DebugLevel } & \odot \\ \text { 2. } & \text { OlsrPort } & 698 \\ \text { 3. } & \text { RtTable } & 254 \\ \text { 4. } & \text { RtTableDefault } & 254 \\ \text { 5. } & \text { MainIp } & 10.10 .10 .1 \\ \text { 6. } & \text { Interface "wlan๑" } \\ \text { 7. } & \\ \text { 8. } & \text { Mode "mesh" } & \\ \text { 9. Ip4Broadcast } & \odot . \odot . \odot . \odot \\ \text { 10. HelloInterval } & 5 . \odot\end{array}$




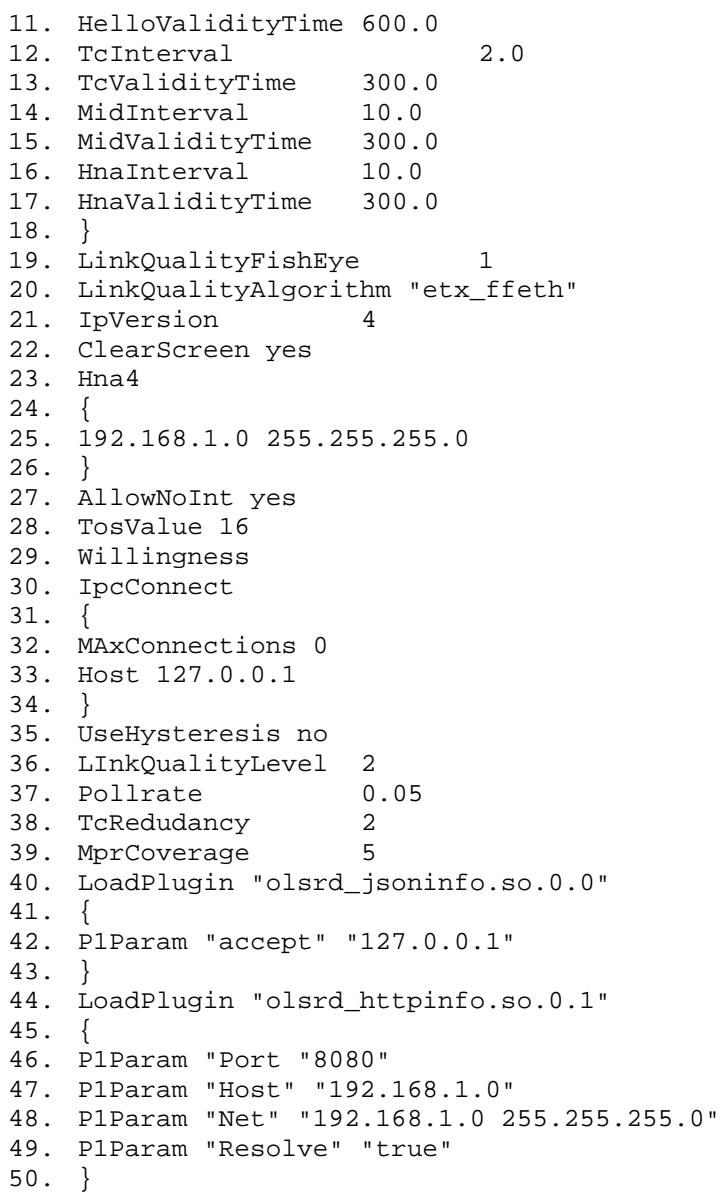

Beberapa konfigurasi yang penting adalah DebugLevel yang diberi nilai 0 . DebugLevel merupakan fungsi kontrol yang mengatur jumlah debug output yang dapat ditampilkan, dengan nilai 0 maka proses yang dijalankan olsrd akan dijalankan dibelakang layar. IpVersion untuk menjelaskan jenis alamat IP yang digunakan pada jaringan, dalam penelitian ini jaringan menggunakan alamat IP versi 4. Interface untuk menunjukkan interface yang digunakan dalam jaringan wireless, yaitu "wlan0". Hna4 merupakan alamat LAN yang dapat berhubungan dengan node router dalam hal ini alamat jaringan 192.168.1.0 dengan netmask 255.255.255.0 sehingga setiap client yang terhubung melalui LAN akan mendapatkan alamat berdasarkan subnet yang sama. MainIp merupakan alamat wireless interfaces dari node router yang akan terhubung dengan node router lainnya, maupun node client yang terhubung melalui koneksi wireless, dalam hal ini alamat wireless interfaces node router 10.10.10.1. Nilai dari HelloInterval adalah 5.0 yang berarti pesan hello akan dikirimkan setiap 5 detik dan poin HelloValidityTime 600.0 berarti waktu valid informasi dalam pesan hello tersebut hingga 600 detik. Kemudian poin TcInterval 2.0 berarti pesan TC (Topology Control) akan dikirim setiap 2 detik dan poin TcValidityTime bernilai 300.0 berarti informasi pesan TC valid hingga 300 detik. 
AITI: Jurnal Teknologi Informasi

Volume 16 No. 2 Agustus 2019, 151-164

\section{Hasil dan Pembahasan}

Skenario untuk pengujian self-configurerouting protokol OLSR pada node router Raspberry Pi digunakan untuk mendapatkan data waktu yang diperlukan suatu node router untuk melakukan self-configure kepada dirinya sendiri dan bergabung dengan jaringan wireless mesh yang sudah ada. Pengujian dilakukan dengan mengubah variabel besarnya interval hellomessage dan TC message dari paket OLSR yang dapat diubah pada file etc/olsrd/olsrd.conf. Skenario pengujian self-configure dapat dilihat pada Gambar 5.

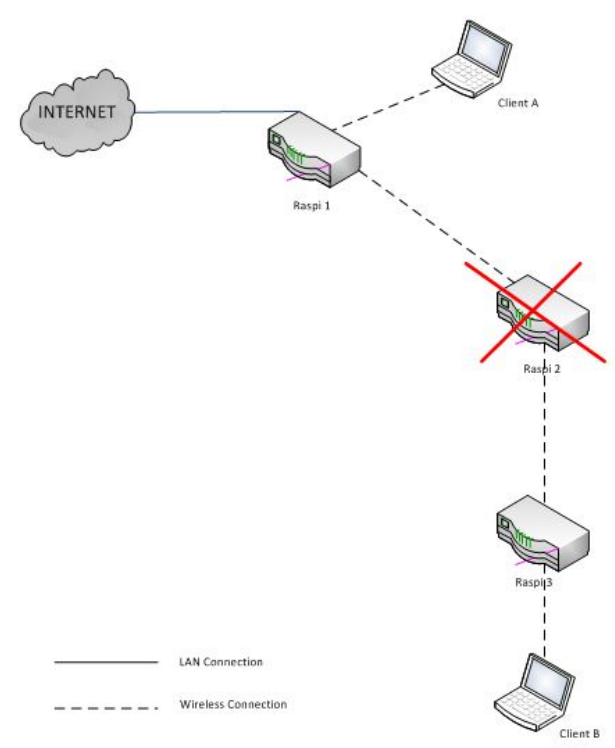

Gambar 5 Skenario Pengujian Self-Configure

Langkah-langkah yang dilakukan pada skenario pengujian self-configure adalah:

- Client A yang terhubung pada wireless mesh network melalui node raspi 1 melakukan hubungan dengan client $\mathrm{B}$ yang terhubung pada node raspi 2 dengan melakukan ping terus menerus.

- Node raspi 3 yang berada diluar jangkauan node raspi 1, karena node raspi 2 dimatikan maka ping akan menghasilkan request time out.

- Kemudian agar node raspi 1 dapat terhubung dengan node raspi 3, maka node raspi 2 dinyalakan.

- Kemampuan node raspi 2 untuk mengkonfigurasi inilah yang disebut dengan kemampuan self-configure.

- Data yang diambil adalah waktu mulai respon replypertama pada clientA yang melakukan ping terus menerus terhadap client B semenjak node raspi 2 dinyalakan.

Hasil dari pengujian self-configure dari wireless mesh networkuntuk nilai interval helloMessage yang berbeda dapat dilihat pada Tabel 1. 
Tabel 1 Tabel Pengujian Self-Configure Untuk Interval HelloMessage

\begin{tabular}{cccc}
\hline No & Hello Interval (detik) & $\begin{array}{c}\text { TC Interval } \\
\text { (detik) }\end{array}$ & Waktu (detik) \\
\hline 1 & 5 & 2 & 43.64 \\
2 & 10 & 2 & 47.26 \\
3 & 15 & 2 & 50.78 \\
4 & 20 & 2 & 53.36 \\
5 & 25 & 2 & 57.58 \\
6 & 30 & 2 & 61.14 \\
\hline
\end{tabular}

Hasil dari pengujian self-configure dari wireless meshnetworkuntuk nilai interval TC (Topology Control) Message yang berbeda dapat dilihat pada Tabel 2.

Tabel 2 Tabel Pengujian Self-Configure Untuk Interval TCMessage

\begin{tabular}{cccc}
\hline No & Hello Interval (detik) & $\begin{array}{c}\text { TC Interval } \\
\text { (detik) }\end{array}$ & Waktu (detik) \\
\hline 1 & 5 & 2 & 42.76 \\
2 & 5 & 5 & 45.84 \\
3 & 5 & 10 & 48.46 \\
4 & 5 & 15 & 50.94 \\
5 & 5 & 20 & 53.96 \\
6 & 5 & 25 & 56.34 \\
7 & 5 & 30 & 59.22 \\
\hline
\end{tabular}

Berdasarkan hasil pengujian yang dilakukan waktu rata-rata yang dibutuhkan untuk self-configure, didapatkan hasil bahwa besarnya nilai interval hellomessage sangat berpengaruh pada waktu yang dibutuhkan untuk melakukan self-configure. Waktu yang diperlukan untuk self-configure ikut bertambah seiring dengan bertambahnya nilai interval hellomessage. Sedangkan untuk besarnya nilai interval TC message tidak seberapa berpengaruh terhadap waktu yang dibutuhkan untuk melakukan self-configure.

Skenario untuk pengujian self-healing routing protokol OLSR pada node router Raspberry Pi digunakan untuk mendapatkan data waktu yang diperlukan jaringan untuk mencari rute baru maupun memperbaiki jalur apabila terjadi kerusakan jalur pada suatu node router. Pengujian dilakukan dengan mengubah variabel besarnya interval hellomessage dan TC message dari paket OLSR yang dapat diubah pada file etc/olsrd/olsrd.conf. Skenario pengujian self-healing dapat dilihat pada Gambar 6. 


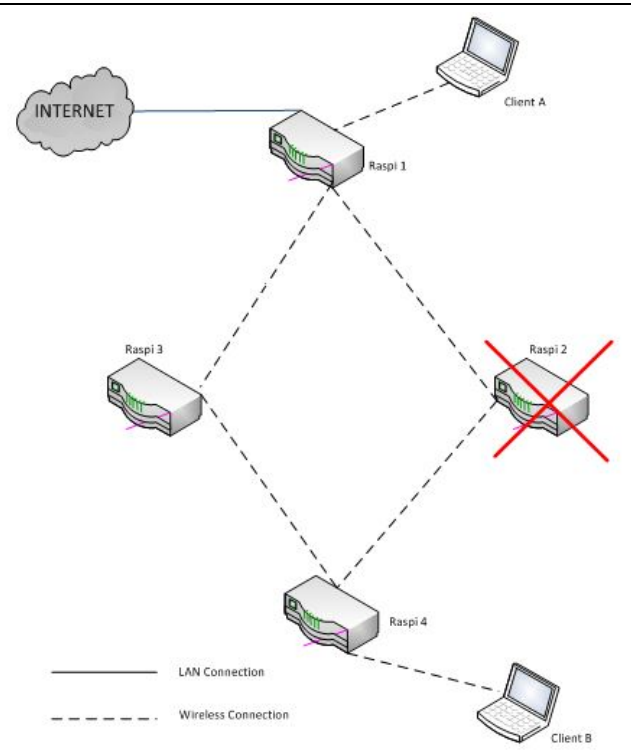

Gambar 6 Skenario Pengujian Self-Healing

Langkah-langkah yang dilakukan dalam skenario pengujian self-healingadalah :

- Client A pada node raspi 1 berhubungan dengan client B yang terhubung dengan node raspi 4 melalui jalur node raspi 2 dengan melakukan ping terus menerus.

- Kemudian node raspi 2 dimatikan, sehingga jalur node raspi 1 ke node raspi 4 melalui node raspi 2 tidak dapat dilalui sehingga ping akan menghasilkan request time out.

- Secara otomatis routing protokol OLSR akan mencari jalur baru melalui node raspi 3 yang masih menyala, inilah yang disebut self-healing.

- Data yang diambil adalah waktu mulai respon reply pertama client A pada node raspi 1 yang melakukan ping terus menerus untuk dapat berhubungan dengan client $\mathrm{B}$ pada node raspi 4 melalui jalur baru yaitu node raspi 3.

Hasil dari pengujian self-healing dari wireless mesh network untuk nilai interval hello message yang berbeda dapat dilihat pada Tabel 3.

Tabel 3 Tabel Pengujian Self-Healing Untuk Interval HelloMessage

\begin{tabular}{cccc}
\hline No & Hello Interval (detik) & $\begin{array}{c}\text { TC Interval } \\
\text { (detik) }\end{array}$ & Waktu (detik) \\
\hline 1 & 5 & 2 & 176.4 \\
2 & 10 & 2 & 181.2 \\
3 & 15 & 2 & 187.6 \\
4 & 20 & 2 & 196.2 \\
5 & 25 & 2 & 200.8 \\
6 & 30 & 2 & 208.6 \\
\hline
\end{tabular}

Hasil dari pengujian self-healing dari jaringan wireless mesh untuk nilai interval TC (Topology Control) Message yang berbeda dapat dilihat pada Tabel 4. 
Tabel 4 Tabel Pengujian Healing Untuk Interval TCMessage

\begin{tabular}{cccc}
\hline No & Hello Interval (detik) & $\begin{array}{c}\text { TC Interval } \\
\text { (detik) }\end{array}$ & Waktu (detik) \\
\hline 1 & 5 & 2 & 175.8 \\
2 & 5 & 5 & 179.4 \\
3 & 5 & 10 & 181.8 \\
4 & 5 & 15 & 182.4 \\
5 & 5 & 20 & 184.6 \\
6 & 5 & 25 & 185.2 \\
7 & 5 & 30 & 187.8 \\
\hline
\end{tabular}

Berdasarkan pengujian self-healing yang dilakukan pada wireless mesh network, sebuah node routerakan secara otomatis mencari jalur sendiri jika terjadi kerusakan pada jalur yang dilalui sebelumnya. Ini terjadi karena routing protokol OLSR akan mendeteksi node tetangga (Neighbour detection), dimana disaat hellomessage dikirimkan tidak ada update informasi tentang suatu node. hellomessage yang tidak diterima lagi update-nya tentang suatu node dalam batas waktu tertentu akan menandakan bahwa hubungan terhadap node tersebut telah putus. Secara otomatis akan mencari jalur baru, dan wireless mesh network akan membentuk topologi baru. Pada clientakan diketahui dengan munculnya request time out pada saat melakukan ping terus menerus.

Skenario untuk pengujian bandwidth routing protokol OLSR pada node router Raspberry Pi berfungsi untuk mendapatkan data pemakaian bandwidth pada masing-masing node router dalam sistem multihop pada jaringan wirelessmesh. Skenario pengujian dilakukan dengan variasi jumlah hop mulai dari 1 hop (R1-R2) dan 2hop (R1-R2-R3) dengan lima kali pengujian pada setiap skenario. Aplikasi Iperf diinstal pada ketiga node router, salah satu node dijadikan server dan node lain menjadi client. Skenario pengujian penggunaan bandwidth dapat dilihat pada Gambar 7.

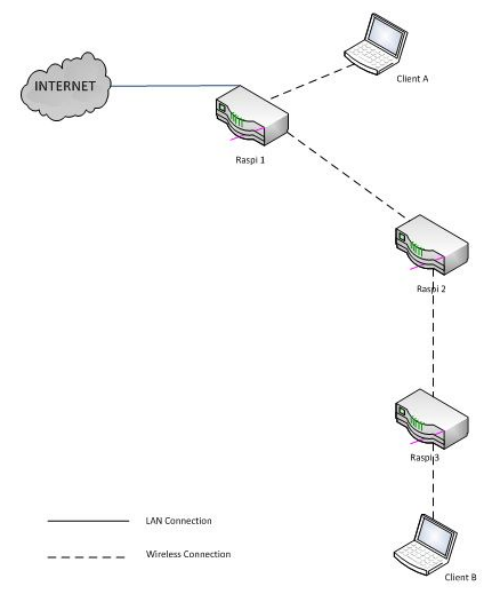

Gambar 7 Skenario Pengujian Bandwidth 
AITI: Jurnal Teknologi Informasi

Volume 16 No. 2 Agustus 2019, 151-164

Hasil pengujian bandwidth dengan jalur 1 hop (R1-R2) dan 2 hop (R1-R2R3) pada wirelessmeshnetwork dapat dilihat pada Tabel 5 dan Tabel 6.

Tabel 5 Tabel Pengujian BandwidthPada Jalur R1-R2

\begin{tabular}{ccccc}
\hline Uji ke- & $\begin{array}{c}\text { Server } \\
\text { Transfer } \\
\text { (Mbytes) }\end{array}$ & $\begin{array}{c}\text { Client } \\
\text { Bandwidth } \\
\text { (Mbits/detik) }\end{array}$ & $\begin{array}{c}\text { Client - Server } \\
\text { Transfer } \\
\text { (Mbytes) }\end{array}$ & $\begin{array}{c}\text { Bandwidth } \\
\text { (Mbits/detik) }\end{array}$ \\
\hline 1 & 17.2 & 14.9 & 17.9 & 15.1 \\
2 & 15.9 & 13.5 & 16.2 & 13.6 \\
3 & 17.0 & 15.0 & 18.0 & 15.1 \\
4 & 14.9 & 13.2 & 15.9 & 13.3 \\
5 & 17.2 & 15.1 & 18.2 & 15.2 \\
\hline Rata- & $\mathbf{1 6 . 4 4}$ & $\mathbf{1 4 . 3 4}$ & $\mathbf{1 7 . 2 4}$ & $\mathbf{1 4 . 4 6}$ \\
rata & & & & \\
\hline
\end{tabular}

Tabel 6Tabel Pengujian Bandwidth Pada Jalur R1-R2-R3

\begin{tabular}{ccccc}
\hline Uji ke- & $\begin{array}{c}\text { Server } \\
\text { Transfer } \\
\text { (Mbytes) }\end{array}$ & $\begin{array}{c}\text { Client } \\
\text { Bandwidth } \\
\text { (Mbits/detik) }\end{array}$ & $\begin{array}{c}\text { Client - Server } \\
\text { Transfer } \\
\text { (Mbytes) }\end{array}$ & $\begin{array}{c}\text { Bandwidth } \\
\text { (Mbits/detik) }\end{array}$ \\
\hline 1 & 7.3 & 6.1 & 7.5 & 6.3 \\
2 & 7.9 & 6.3 & 8.2 & 6.8 \\
3 & 7.3 & 6.1 & 7.5 & 6.3 \\
4 & 8.2 & 6.8 & 8.6 & 7.2 \\
5 & 7.7 & 6.6 & 8.4 & 7.1 \\
\hline $\begin{array}{c}\text { Rata- } \\
\text { rata }\end{array}$ & $\mathbf{7 . 6 8}$ & $\mathbf{6 . 3 8}$ & $\mathbf{8 . 0 4}$ & $\mathbf{6 . 7 4}$ \\
\hline
\end{tabular}

Berdasarkan hasil pengujian bandwidth antara dua jalur yaitu R1-R2 dengan R1-R2-R3 didapatkan hasil bahwa besarnya bandwidth dipengaruhi oleh banyaknya hop yang dilewati. Pada pengujian bandwidth dengan jalur R1-R2 (1 hop) didapatkan nilai rata-rata bandwidth sebesar $14.34 \mathrm{Mbit} / \mathrm{s}$ dengan besar transfer 16.44 Mbytes (Server-Client) dan 14.46 Mbit/s dengan besar transfer 17.24 Mbytes (Client-Server). Sedangkan untuk jalur R1-R2-R3 (2 hop) didapatkan nilai rata-rata bandwidth yang lebih kecil yaitu $6.38 \mathrm{Mbit} / \mathrm{s}$ dengan besar transfer 7.68 Mbytes (Server-Client) dan 6.74 Mbit/s dengan besar transfer 8.04 Mbytes (ClientServer).

\section{Simpulan}

Berdasarkan hasil analisis, perancangan dan pengujian kinerja routing protokol OLSR pada Raspberry Pi dalamwireless mesh network, yang telah dijelaskan pada bab sebelumnya, dapat diambil kesimpulan bahwa node mesh yang digunakan yaitu Raspberry Pi juga dapat menggantikan fungsi router yaitu mampu merutekan trafik dari sumber ke tujuan.Penggunaan routing protokol OLSR pada Raspberry Pi dalamwireless mesh network terbukti dapat memperbaiki dirinya sendiri jika ada masalah pada perangkat jaringannya karena memiliki kemampuan self-configure dan self-healing, besarnya nilai interval hello message lebih berpengaruh terhadap performansi self-configure pada wireless mesh network 
dibandingkan besarnya nilai interval TC message, karena semakin besar nilai interval hellomessage maka waktu kerja self-configure semakin lama, nilai bandwidth pada jaringan wireless mesh sangat dipengaruhi oleh jumlah hop yang dilalui.

Saran yang dapat diberikan untuk penelitian dan pengembangan selanjutnya adalah memperhatikan keamanan pada wireless mesh network dan penggunaan jumlah node router dan client yang lebih banyak.

\section{Daftar Pustaka}

[1]. Purbo, Onno W., 2014, Optimized Link State Protocol(OLSR), http://cyberlearning.web.id/wiki/index.php/OLSR. Diakses pada 1 April 2016.

[2]. Mardani, Bagus, 2008,Analisis Unjuk Kerja Wireless Mesh Network Dengan Routing Protocol OLSR. Skripsi, Depok :JurusanTeknik Elektro Universitas Indonesia.

[3]. Setyawan, Adnan Puguh, 2014,Analisis Dan Perancangan Wireless Mesh Networking Menggunakan OLSR (Optimized Link State Routing) Berbasis OpenWRT Di Jogja Digital Valley. Skripsi, Yogyakarta :Jurusan Teknik Informatika Sekolah Tinggi Manajemen Informatika Dan Komputer AMIKOM Yogyakarta.

[4]. Akyildiz, Ian F., dkk., 2005, Wireless Mesh Networks: a survey, Georgia Institute of Technology.

[5]. Purbo, Onno W., 2013, Jaringan MESH: Solusi Jitu Membangun Jaringan Wireless Gotong Royong Tanpa Access Point, Andi Publisher.

[6]. Clausen, dkk., 2003, RFC 3626 :Optimized Link State Protocol(OLSR), https://www.ietf.org/rfc/rfc3626.txt. Diakses pada 1 April 2016. 